\title{
Being overburdened and medically underserved: assessment of this double disparity for populations in the state of Maryland
}

Sacoby Wilson ${ }^{1,2^{*}}$, Hongmei Zhang ${ }^{3}$, Chengsheng Jiang ${ }^{1,2}$, Kristen Burwell ${ }^{1,2}$, Rebecca Rehr ${ }^{1,2}$, Rianna Murray ${ }^{1,2}$, Laura Dalemarre ${ }^{1,2}$ and Charles Naney ${ }^{1}$

\begin{abstract}
Background: Environmental justice research has shown that many communities of color and low-income persons are differentially burdened by noxious land uses including Toxic Release Inventory (TRI) facilities. However, limited work has been performed to assess how these populations tend to be both overburdened and medically underserved. We explored this "double disparity" for the first time in Maryland.

Methods: We assessed spatial disparities in the distribution of TRI facilities in Maryland across varying levels of sociodemographic composition using 2010 US Census Health Professional Shortage Area (HPSA) data. Univariate and multivariate regression in addition to geographic information systems (GIS) were used to examine relationships between sociodemographic measures and location of TRI facilities. Buffer analysis was also used to assess spatial disparities. Four buffer categories included: 1) census tracts hosting one or more TRI facilities; 2) tracts located more than 0 and up to $0.5 \mathrm{~km}$ from the closest TRI facility; 3) tracts located more than $0.5 \mathrm{~km}$ and up to $1 \mathrm{~km}$ from a TRI facility; and 4) tracts located more than $1 \mathrm{~km}$ and up to $5 \mathrm{~km}$ from a TRI facility.

Results: We found that tracts with higher proportions of non-white residents and people living in poverty were more likely to be closer to TRI facilities. A significant increase in income was observed with an increase in distance between a census tract and the closest TRI facility. In general, percent non-white was higher in HPSA tracts that host at least one TRI facility than in non-HPSA tracts that host at least one TRI facility. Additionally, percent poverty, unemployment, less than high school education, and homes built pre-1950 were higher in HPSA tracts hosting TRI facilities than in non-HPSA tracts hosting TRI facilities.
\end{abstract}

Conclusions: We found that people of color and low-income groups are differentially burdened by TRI facilities in Maryland. We also found that both low-income groups and persons without a high school education are both overburdened and medically underserved. The results of this study provide insight into how state agencies can better address the double disparity of disproportionate environmental hazards and limited access to health care resources facing vulnerable communities in Maryland.

\footnotetext{
* Correspondence: swilson2@umd.edu

${ }^{1}$ Community Engagement, Environmental Justice and Health, University of

Maryland-College Park, College Park, MD 20742, USA

${ }^{2}$ Maryland Institute for Applied Environmental Health, University of

Maryland-College Park, College Park, MD 20742, USA

Full list of author information is available at the end of the article
} 


\section{Introduction}

Environmental injustice is driven by privilege, power- particularly structural and environmental racism which are embedded in our regulatory schema, zoning, planning and community development processes [1,2]. Additionally, unhealthy geographies that concentrate environmental, social, and health risks in urban and rural areas are produced and are known as 'riskscapes' [3,4]. The original Toxic Waste and Race in America report published in 1987, was the first report to demonstrate that many economically underserved populations and people of color communities are disproportionately impacted by locally unwanted land uses (LULUs) [5]. Since the 1987 report and the recent twenty-year anniversary report [5], researchers have shown that these disparities persist, with low-income persons and populations of color continuing to live in communities with a differential burden of LULUs including toxic release inventory (TRI) facilities [6-18], landfills [5], incinerators [5], hazardous waste sites [5,18], sewer and water infrastructure including sewer and water treatment plants $[7,8,19,20]$, coal-fired plants [5], industrial animal operations [21,22], and Superfund sites [23-25]. This disproportionate burden can lead to increased exposure to harmful environmental conditions and chemical, physical, and biological agents for impacted communities [1,2,26-28].

Previous research has also shown that populations of color and low-income groups living in poor environmental conditions have health risks due in part to various social determinants of health including segregation, racism, socioeconomic status (SES), income inequality, and inequities in planning and zoning [1-4,6,14,19,20,28-31]. Studies have shown that underlying social and economic vulnerabilities contribute to increased health disparities [29,31,32], which further enhance the long-term effects of environmental injustice. Environmental justice communities are also affected by a higher concentration of psychosocial stress $[1,28,29]$ that can lead to an increase in community-level and individual-level stress.

A potential environmental justice issue in the state of Maryland is the distribution and concentration of TRI facilities. Previous studies in New York [7], South Carolina $[9,10]$, Oregon $[11,12]$, California $[13,18]$, and the entire United States $[6,8,15]$ have demonstrated the disproportionate burden of TRI facilities in low-income and nonwhite communities (often using census tracts as the unit of analysis). Ringquist found that TRI facilities were found in zip codes with large populations of people of color [15]. Racial composition of neighborhood was found to be a stronger contributor to the trend associated with the distribution of environmental risk than class [15]. Abel found that people of color and low-income residents were disproportionately closer to TRI facilities in metropolitan St. Louis [16]. Spatial concentration of residents of color averaged nearly $40 \%$ within one $\mathrm{km}$ of St. Louis TRI sites compared to $25 \%$ in other locations [16]. Fricker and Hengarter report that the racial/ethnic composition of a census tract in Metropolitan New York was positively associated with the presence of LULUs including TRI sites [7]. In metropolitan New York, the Hispanic population resided in neighborhoods closer to undesirable sites than other racial/ethnic groups [7]. Using 1990 US Census and 1990 TRI data, Daniels and Friedman observed a positive relationship between proportion Black residents and toxic releases to air [17].

Wilson et al. found significant burden disparities [9], where more TRI facilities were located in census tracts with higher non-white and low-income populations for the state of South Carolina and Metropolitan Charleston. In addition to this work, other researchers have documented similar racial and income disparities among communities hosting TRI facilities [11,12]. Neumann et al discovered that TRI facilities were located disproportionately in people of color neighborhoods and in areas with lower incomes compared to those in the surrounding counties [11].

Miranda et al. took these analyses one step further to scrutinize the effects of new TRI reporting requirements implemented in December 2006 which reduced reporting requirements for certain chemicals released in limited quantities [33]. Specifically, the study found that facilities given permissions to use a short reporting form were disproportionately located in majority non-white census tracts [33]. As a result, residents were losing access to salient information regarding chemical releases compared to their white counterparts who were mostly located in areas with more stringent reporting requirements.

The paucity of information on chemical releases is problematic because many of the chemicals typically emitted by TRI facilities and other LULUs have been linked to adverse cancer and non-cancer health effects $[34,35]$ which may significantly impact people who live near these environmental hazards. For example, emissions from TRI facilities may include harmful substances such as benzene, cadmium, toluene, and mercury, among other chemicals [36,37]. Moreover, populations exposed to TRI-related chemicals may have an increased risk of adverse health outcomes such as low birth weight, asthma, and cancer [13,38-40] estimated by previous research using risk assessment methodology.

In addition to being differentially burdened by environmental hazards and LULUs, the lack of access to salutogenic infrastructure (e.g., positive and health-promoting features of the built and social environment) $[1,2,41]$ is a major environmental justice issue for people of color communities and economically disadvantaged populations. Many persons of color live in socially disadvantaged areas with limited access to primary care resources [42-46]. 
Access to adequate healthcare may be a major problem for economically disadvantaged in communities with preexisting burden, exposure, and environmental health disparities. A growing body of literature has examined the distribution of health enriching resources and medical care services across varying racial/ethnic and SES composition at the neighborhood level. Limited access to hospitals and medical professionals and lower quality of care both play major roles in health outcomes and disparities in disadvantaged neighborhoods [47-52]. Being both disadvantaged and medically underserved means disadvantaged populations may have higher rates of chronic conditions, more drug use, emotional problems, and worse health behaviors than other populations [53], but lack of access to competent high quality care may mean lower immunizations rates for children [54] and more hospitalizations for treatable and preventable conditions [55]. Taken as a whole, the differential burden of pollutogens and access to salutogenic resources has important implications for health and environmental health disparities $[1,2,41]$.

The issue of how people of color neighborhoods and low-income populations are disproportionately burdened by LULUs such as TRI facilities and are potentially underserved due to poor access to medical infrastructure is important for a state like Maryland with a number of racial/ ethnic and SES-related health disparities. The 2010 MD Plan to Eliminate Minority Health Disparities (MPEMHD) lists racial/ethnic disparities in healthcare utilization, access to primary care, and the burden of all-cause mortality, heart disease, renal disease, hypertension, obesity, HIV/ AIDS, and asthma as critical areas for improvement [56]. Three of the four counties in MD with the highest population of persons of color (Baltimore City, Charles County, Montgomery County, and Prince George's County) all have more than $50 \%$ non-white residents and the highest total environmental releases (Charles County, Prince George's, and Baltimore City) [56]. As further proof that these health disparities are a serious problem, the Maryland Health Improvement and Health Disparities Reduction Act (MHIHDRA) was recently passed to address the aforementioned disparities [56].

In addition, the MD Department of Health and Mental Hygiene (MDHMH) uses its Environmental Public Health Tracking Network (EPHTN) to offer web-based data sharing tools for residents, policymakers, and other public officials to create their own maps and charts documenting environmental health disparities in their service areas $[57,58]$. Information available for analysis through the MD EPHTN includes the following: 1) childhood blood level testing, 2) myocardial infarction and asthma-related hospitalization data, and 3) low birth weight from state birth certificate records [57]. Thus, running a query reveals significant disparities in blood lead levels among counties; with Baltimore City having a much higher rate than other counties (449 1-year olds in 2008 had elevated blood lead levels versus many other counties that had none) [59]. Another query revealed that asthma hospitalization discharge rates were higher among blacks compared to whites across the state (36.79 per 10,000 vs. 11.20 per 10,000 , respectively), and this disparity was more pronounced in certain areas (32.33 per 10,000 vs. 2.88 per 10,000 in Baltimore City and 10.31 per 10,000 vs. 1.00 per 10,000$)$ [56,59].

The purpose of this study was to assess whether TRI facilities in Maryland were more likely to be located in census tracts with higher proportions of black, nonwhite, low-income, or less educated persons. In addition, we assessed whether populations near TRI facilities had limited access to health care infrastructure as indicated by health professional shortage area (HPSA) designation at the census tract level. By assessing both presence of TRI facilities and HPSA designation, we assessed the potential "double disparity" of being environmentally overburdened and underserved in terms of health care access across neighborhoods with varying sociodemographic composition.

\section{Methods and materials Study area}

The state of Maryland (MD) is ranked $42^{\text {nd }}$ in size among states in the U.S., but $19^{\text {th }}$ in population, which makes it one of the more densely populated states in the nation [60]. The population within MD is concentrated in two main areas: 1) around the harbor in Baltimore County and Baltimore City and 2) Montgomery County and Prince George's County, MD near Washington, DC. According to the 2010 US Census, there were 5,773,552 people living in MD with $61.1 \%$ white and $30.0 \%$ black [60]. Furthermore, populations of color living in MD are highly concentrated in these two areas. Baltimore City is $72 \%$ non-white and Prince George's County is $85 \%$ non-white, while MD is $39 \%$ non-white as a whole [60].

The number of people living in poverty is also unevenly distributed throughout the state. For example, Maryland ranks $3^{\text {rd }}$ in the nation in median household $(\mathrm{HH})$ income with only $8.6 \%$ of the state living in poverty (compared to $13.8 \%$ nationwide) [60]. In Baltimore City, the most densely populated urban area in the state, $21.3 \%$ of residents live below the federal poverty line [60]. In two other distinct parts of the state, Allegany County in western MD has $14.5 \%$ of its residents living in poverty and Dorchester County on the eastern shore has $13.4 \%$, both well above the state poverty rate [60].

\section{Sociodemographic (SOD) Measures}

This study used key demographics for MD modeled as quartiles from 2010 census data [9,61,62]. While SOD information is available at various geographic scales (ZIP code tabulation areas (ZCTAs), tracts, block groups, and 
blocks), we utilized census data at the tract level to enumerate the following population characteristics: race/ ethnicity (\% non-white includes all other races including Hispanics except non-Hispanic white; and \% Hispanic) and variables related to socioeconomic status (SES). SOD measures included in our study were poverty (\% population below poverty line), education (\% population age greater than 25 years with < high school (HS) education), unemployment (\% of population 16 years and older who were unemployed), homeownership (\% of homes occupied by owners), and homes built before 1950 (\% of homes built pre-1950). The variable related to income was median $\mathrm{HH}$ income. Median $\mathrm{HH}$ income, \% poverty, house construction year, \% unemployment and educational attainment (i.e., \% without a HS diploma) were calculated using the 2006 to 2010 American Community Survey (ACS) 5-year estimates.

\section{USA today diversity index}

The USA Today Diversity equation measures the distribution of multiple races. Specifically, it calculates the probability that any two people randomly selected in an area are from different races or ethnic groups [63]:

$$
\text { USA Today Diversity }=1-\left(\left(1-\mathrm{q}_{\mathrm{h}}\right)^{2}+\mathrm{q}_{\mathrm{h}}^{2}\right) \times \sum \mathrm{p}_{1}^{2}
$$

where $\mathrm{q}_{\mathrm{h}}$ is the $\%$ of Hispanics in an area and $\mathrm{p}_{\mathrm{i}}$ includes $\%$ White, African-American, Asian, American Indian and Alaska Native, and Native Hawaiian and other Pacific Islander. The higher the Diversity Index, the more diverse a population in a particular region ranged from 0 to 100 . The Diversity Index is well-suited for characterizing racial and ethnic diversity at the tract level, while other indices are more appropriate for examining segregation at larger geographic scales, such as the MSA. In this study, the Diversity Index was calculated at the census tract level.

\section{Toxics release inventory (TRI)}

The TRI database was established by Section 313 of the 1986 Emergency Planning and Community Right-toKnow Act (EPCRA) [64]. Estimations of the mass of disposal or other release of over 650 chemicals were reported to the TRI by each facility (2010 Toxics Release Inventory national analysis overview). The 2010 single Facility Registry System (FRS) state files were downloaded from the USEPA and TRI facilities were selected from the FRS which contains their respective latitude and longitude coordinates. Distance between a TRI facility and nearest census tract was calculated in ArcGIS 10 (esri, Redlands, CA). A TRI facility located in a census tract or on the boundary of the census tract was assigned a distance of 0 which means that the census tract 'hosts' the TRI facility.

\section{Healthcare infrastructure}

The Department of Health and Human Services (DHHS) created Health Professional Shortage Area (HPSA) designation to identify areas facing a critical shortage of providers $[42-46,65]$. A HPSA can be a distinct geographic area (such as a county), a specific population group within an area (such as low-income individuals), or a specific health care facility [66]. We obtained 2010 HPSA data for the state of Maryland and categorized each census tract in Maryland either as a HPSA census tract or non-HPSA census tract.

\section{Statistical and geographic methods}

To assess the proximity from TRI facilities to different sociodemographic features, we used two approaches. In the first approach, census tracts were grouped by their distance to the nearest TRI facility. A distance was measured along a straight-line path between a facility and the point closest to the facility on the boundary of a census tract. Based on this definition, we grouped census tracts into four groups (or four distance bands), defined as: band 1 composed of census tracts hosting one or more TRI facilities (at least one TRI in the census tract and the distance was 0 ), band 2 included census tracts whose distance to the closest TRI facility was greater than 0 and up to $0.5 \mathrm{~km}$, band 3 greater than $0.5 \mathrm{~km}$ and up to $1 \mathrm{~km}$, and finally band 4 greater than $1 \mathrm{~km}$ and up to $5 \mathrm{~km}$. Census tracts whose distance to the nearest TRI facility was greater than $5 \mathrm{~km}$ but within $10 \mathrm{~km}$ were excluded from this analysis due to the small number of census tracts in this distance band. Then within each band, the mean percentage of each SOD measure for those census tracts was calculated. This task was performed to evaluate how SOD composition changed with the change in distance. When disproportionality did not exist with respect to a specific SOD group, we expected that the mean SOD measure (by percentage) in each distance band would correspond to the mean percentage calculated for the entire state. Student t-tests were used to test this hypothesis of equality.

In the second approach, census tracts were grouped based on the percent number for a specific SOD variable. This was done to evaluate how distance changed with respect to the change in the composition of population for a specific SOD group. To this end, we divided the census tracts into four groups (Q1 to Q4) using quartiles of a SOD variable measured by percentage across the state of Maryland. Then in each group of census tracts, the average distance between each tract and the closest TRI facility was calculated.

To quantify the relationship between the distribution of TRI facilities and SOD factors at the census tract level, we first applied univariate linear regression to test the association of distance from census tracts to the 
closest TRI facility (dependent variable) with each individual SOD factor (independent variable). This was then followed by a multivariable linear regression model with all SOD factors included in order to each SOD factor's effect after adjusting for other SOD factors, i.e., $y_{i}=\beta_{0}+\beta^{T} X+\varepsilon_{i}$ where $y_{i}$ denotes distance, $\boldsymbol{X}$ denotes a vector of SOD factors, the $\boldsymbol{\beta}$ vector is for the SOD factor effects, and $\varepsilon$ is the random error. To eliminate redundant variables, a stepwise variable selection approach based on the Bayesian Information Criterion (BIC) was applied to finally select the most important variables.

We hypothesized that low-income and people of color communities are both overburdened by environmental hazards and unhealthy land uses and underserved by health infrastructure known as the "double disparity". To test the difference in SOD composition between HPSA tracts and non-HPSA tracts, we compared the average SOD measures in HPSA tracts and non-HPSA tracts in two distance band areas, one area covered census tracts hosting a TRI facility and the other area including census tracts within $1 \mathrm{~km}$ to $5 \mathrm{~km}$ to the nearest TRI facility. For each area, a student t-test was used to test the difference in composition for each SOD measure between HPSA tracts and non-HPSA tracts.

All of the above calculations and hypothesis testing were performed using $\mathrm{R}$ version 2.15.0 [11,12,67]. Statistical significance level was set at 0.05 . TRI facilities were mapped and overlaid by select SOD features (\% nonwhite and \% poverty) in ArcGIS 10 (esri, Redlands, CA). Choropleth maps were created to illustrate the spatial relationship between TRI facilities and sociodemographic composition using quartiles.

\section{Results}

Figures 1 and 2 were created to show the spatial distribution of TRI facilities in relation to composition of various sociodemographic groups at the census tract level. There were 525 TRI facilities located in 259 census tracts in MD out of a total of 1390 census tracts. In addition, there was one census tract located close to the Port in South Baltimore that hosts 14 TRI facilities which was the largest number of TRI facilities found in one tract in the state. The choropleth maps show clusters of TRI facilities in the Baltimore Metropolitan Statistical Area (MSA), Washington County (western MD), and Wicomico County (Eastern Shore).

For the purpose of this analysis, we only present mapping results for $\%$ non-white and \% poverty due to the fact that previous studies have shown a positive relationship between number of TRI facilities and presence of non-whites and low-income persons. For \% non-white, 137 TRI facilities were located in the first quartile followed by 165,164 , and 47 facilities in the second,

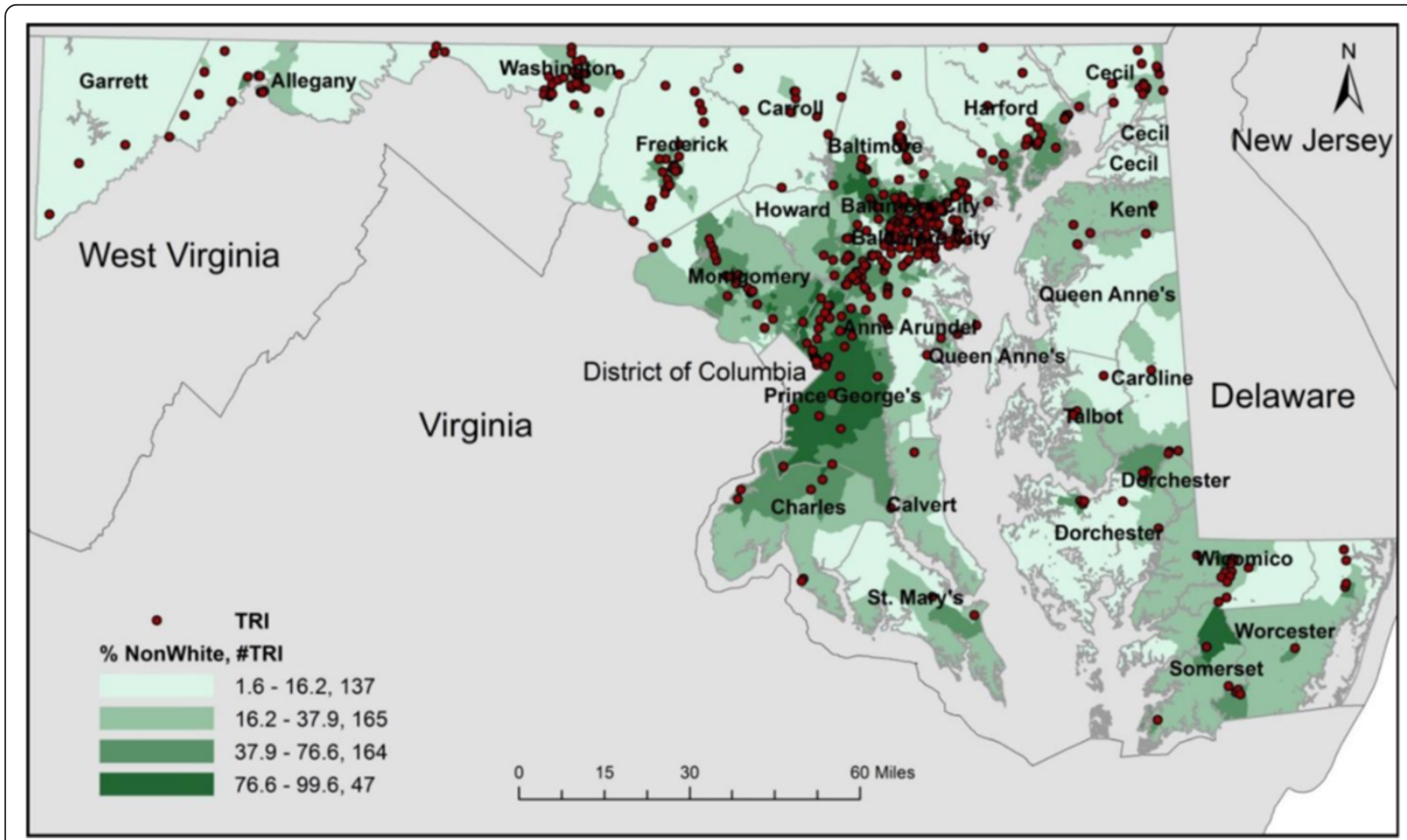

Figure 1 Choropleth Map of TRI Facilities in Maryland by Quartiles for Percent Non-White (2010 US Census). 


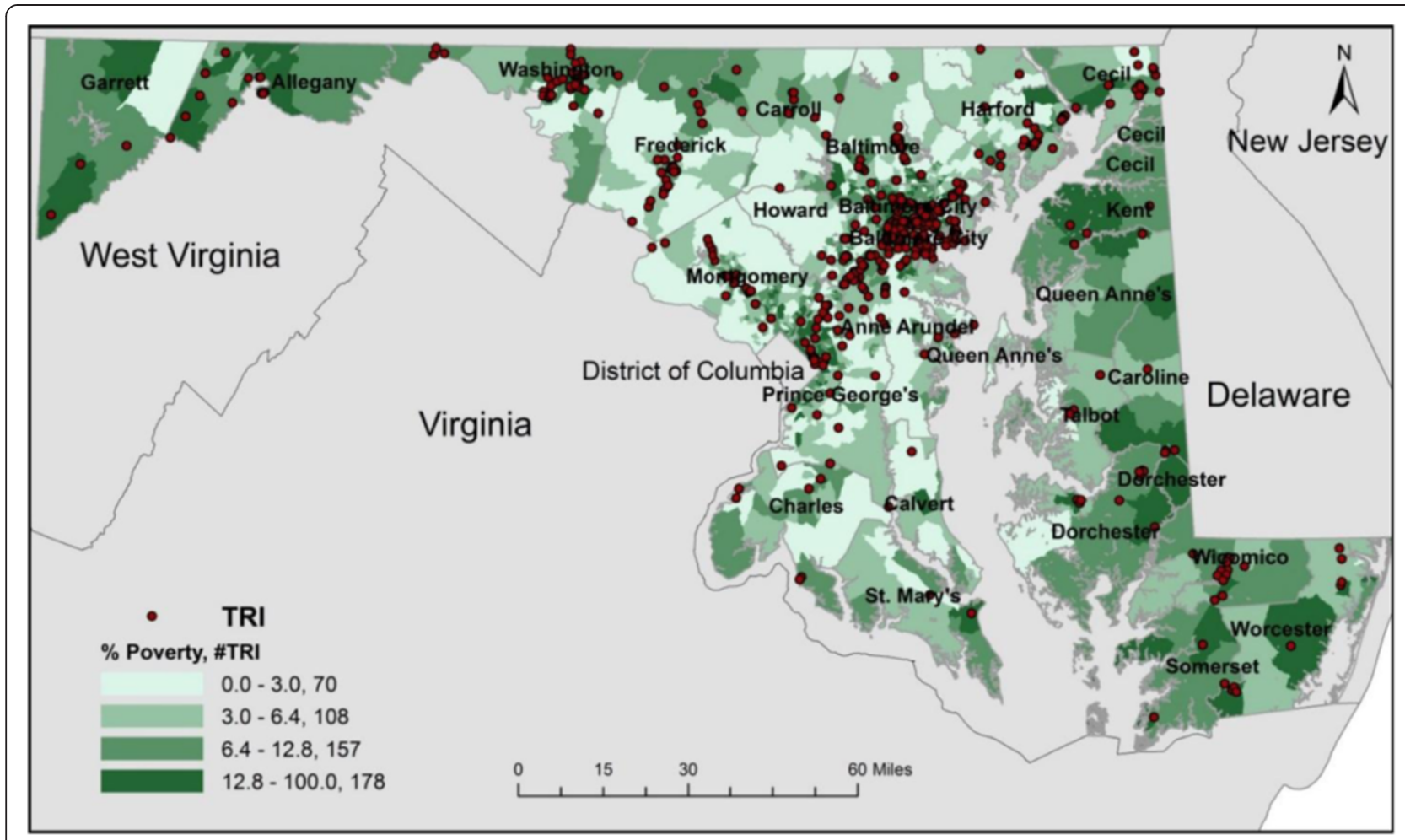

Figure 2 Choropleth map of TRI facilities in Maryland by quartiles for percent poverty (2010 US census).

third, and fourth quartiles, respectively. There were 12 TRI facilities not included on the maps due to a locational error or they were located in census tracts where no people lived. The census tracts in the fourth quartile had the largest non-white population but the fewest TRI facilities compared to other quartiles. Regarding \% living in poverty, 70 TRI facilities were located in the first quartile followed by 108, 157, and 178 facilities in the second, third, and fourth quartiles, respectively. Both figures show evidence of differences in the concentration of TRI facilities across varying levels of sociodemographic composition at the census tract level. Figure 2 indicated a clear linear relationship between \% living in poverty and TRI facilities. Thus, as \% persons in poverty increased, the number of TRI facilities increased.

Statistical summaries and tests indicated that the population distribution for different SOD variables changed with an increase in distance to TRI facilities (Table 1). For example, mean \% non-white in census tracts having at least one TRI facility in their geographic boundary (host)

Table 1 Mean distribution of sociodemographic measures by TRI facility buffer zones in Maryland (2010 census)

\begin{tabular}{lccccc}
\hline Sociodemographic measure & State & Host (a census tract that hosts at least one TRI facility) & $\mathbf{0 - 0 . 5} \mathbf{~ k m}$ & $\mathbf{0 . 5 - 1 . 0 ~} \mathbf{~ m}$ & $\mathbf{1 - 5 . 0} \mathbf{~ k m}$ \\
\hline \% Hispanic & 7.8 & 6.9 & 8.5 & 7.8 & 8.6 \\
\hline \% Non-white & 46.1 & $38.4^{* *}$ & 49.2 & $54.8^{* *}$ & 49.1 \\
\hline \% Poverty & 9.6 & $11^{*}$ & 10.8 & $12.7^{* *}$ & $8.3^{*}$ \\
\hline \% Unemployment & 7.1 & 7.2 & $8^{* *}$ & $8.3^{* *}$ & $6.6^{*}$ \\
\hline \% $<$ HS education & 13.2 & $15.3^{* *}$ & 14.6 & $16^{* *}$ & $11.7^{* *}$ \\
\hline \% Homeownership & 67.1 & 65.3 & $63.3^{*}$ & $59.3^{* *}$ & 68.9 \\
\hline \% Homes built pre-1950 & 20.8 & $25.4^{* *}$ & $24.6^{*}$ & $28.7^{* *}$ & $16.9^{* *}$ \\
\hline Diversity index & 0.43 & 0.43 & $0.46^{*}$ & 0.43 & 0.44 \\
\hline Median HH income & 74810 & $65239^{* *}$ & $69399^{*}$ & $64362^{* *}$ & $81190^{* *}$ \\
\hline MD census tracts (N) & 1390 & 259 & 218 & 192 & 613 \\
\hline
\end{tabular}


(38.4\%) was significantly lower than the mean \% nonwhite in all census tracts in Maryland. With an increase in distance to the nearest TRI facility, \% non-white increased and becomes statistically significantly higher than the statewide mean for \% non-white. The census tracts with distance to the nearest TRI facility in the third distance band ( $>0.5 \mathrm{~km}$ and $<1 \mathrm{~km}$ ) had the highest \% non-white (54.8\%) which was $8.7 \%$ higher than the statewide average Results indicate that on average, the highest proportion of non-white residents was in tracts that were between 0.5 $1 \mathrm{~km}$ distance from a TRI facility. However, there was no statistically significant difference between statewide mean $\%$ Hispanic and mean \% Hispanic in host tracts or other tracts grouped by distance.

Percent living in poverty in host tracts and \% poverty of census tracts in the second distance band was almost the same (11\% and $10.8 \%$, respectively). They both were higher than the statewide average (9.6\%). Percent living in poverty increased to $12.7 \%$ in the third distance band $(>0.5 \mathrm{~km}$ and $<1 \mathrm{~km}$ ) and decreased to $8.3 \%$ for the fourth distance band ( $>1 \mathrm{~km}$ and $<5 \mathrm{~km}$ ). In addition, these results reveal that there were more persons in poverty living in areas closer to TRI facilities especially in census tracts within the third distance band $(>0.5 \mathrm{~km}$ and $<1 \mathrm{~km}$ ). We observed a similar pattern for changes in \% less than HS education as distance from census tracts to the nearest TRI facility increased (Table 1). For $\%$ unemployment, there were no statistically significant differences between statewide average percentage and in areas hosting TRI facilities $\mathbf{7 . 1 \%}$ for statewide average and $7.2 \%$ for host tracts).

For housing-related variables, we observed lower \% homeownership in host tracts compared to the statewide average, but the difference was not statistically significant. As the distance from census tracts to the nearest TRI facility increased, mean \% homeownership decreased from $63.3 \%$ to $59.3 \%$ from the second distance band ( $>0 \mathrm{~km}$ and $<0.5 \mathrm{~km}$ ) to the third distance band $(>0.5 \mathrm{~km}$ and $<1 \mathrm{~km}$ ) both of which were statistically lower than the statewide average (67.1\%). After $1 \mathrm{~km}, \%$ homeownership increased to $68.9 \%$ which was $1.8 \%$ higher than the statewide average. The changes in $\%$ homes built pre-1950 were similar to changes in \% poverty (Table 1).

As for the Diversity index, no clear pattern was observed. Statistically significant differences were observed in the $0-0.5 \mathrm{~km}$ buffer (0.46). At the census tract level, the statewide average median $\mathrm{HH}$ income $(\$ 74,810)$ was almost $\$ 10,000$ higher than median $\mathrm{HH}$ income for census tracts hosting a TRI facility and in areas in the second distance band $(>0.5 \mathrm{~km}$ and $<1 \mathrm{~km})$. The median $\mathrm{HH}$ income increased to $\$ 81,190$ in areas in the fourth distance band ( $>1 \mathrm{~km}$ and $<5 \mathrm{~km}$ ). These results indicate that TRI facilities possibly cluster in low-income areas that host the LULU or in areas located at least $1 \mathrm{~km}$ away from the nearest TRI facility.

Table 2 shows the mean distance between TRI facilities and each group of census tracts defined by quartiles of SOD measures. When considering race, the mean distance from TRI facilities to census tracts grouped by $\%$ Hispanic from Q1 to Q4 decreased 20\%, while \% nonwhite from Q1 to Q4 decreased 40\% (2.5 km vs $1.5 \mathrm{~km})$. These results indicate that census tracts with a higher $\%$ non-white population were located closer to TRI facilities. For \% poverty, the mean distance from census tracts to the nearest TRI facility decreased 50\% from Q1 to Q4. A similar pattern in distance change across different quartile groups of census tracts was observed for \% unemployment and \% less than HS education (Table 2). As for \% homeownership, the higher the percentage, the farther the distance to the nearest TRI facility (mean distance of $1.2 \mathrm{~km}$ for Q1 and $2.7 \mathrm{~km}$ for Q4). Percent homes built pre-1950 showed a non-linear pattern. The distance first increased from Q1 to Q2, and then decreased from Q3 to Q4. The Diversity index showed a decreasing pattern of distance from Q1 to Q4, consistent with the pattern revealed by $\%$ poverty, $\%$ unemployment, and \% less than HS education. The mean distance to the nearest TRI facility for census tracts grouped by quartiles of median $\mathrm{HH}$ income showed a linear increase

Table 2 Mean distance to TRI facilities by quartiles for various sociodemographic measures in Maryland (2010 census)

\begin{tabular}{|c|c|c|c|c|c|}
\hline Sociodemographic measures & Q1 (km) & Q2 (km) & Q3 (km) & Q4 (km) & Q4/Q1 \\
\hline$\%$ Hispanic & 2.1 & 1.9 & 1.6 & 1.6 & 0.8 \\
\hline$\%$ Non-white & 2.5 & 1.7 & 1.4 & 1.5 & 0.6 \\
\hline$\%$ Poverty & 2.3 & 1.9 & 1.8 & 1.1 & 0.5 \\
\hline \% Unemployment & 2.2 & 1.9 & 1.8 & 1.3 & 0.6 \\
\hline$\%<$ HS education & 2.3 & 2.2 & 1.7 & 1 & 0.4 \\
\hline \% Homeownership & 1.2 & 1.3 & 2 & 2.7 & 2.3 \\
\hline$\%$ Homes built pre-1950 & 2 & 2.2 & 1.8 & 1.1 & 0.6 \\
\hline Diversity index & 2.2 & 2 & 1.4 & 1.4 & 0.6 \\
\hline Median $\mathrm{HH}$ income & 1.1 & 1.5 & 1.9 & 2.6 & 2.4 \\
\hline
\end{tabular}


Table 3 Linear regression of decay in distance to TRI facilities by exposure factors in Maryland (2010)

\begin{tabular}{|c|c|c|c|c|}
\hline \multirow[b]{2}{*}{ Sociodemographic measures } & \multicolumn{2}{|c|}{ Univariate linear regression } & \multicolumn{2}{|c|}{ Multivariate linear regression } \\
\hline & Beta coefficient & $p$-value & Beta coefficient & $\mathrm{p}$-value \\
\hline$\%$ Hispanic & -0.014 & 0.01 & 0.028 & $<0.001$ \\
\hline$\%$ Non-white & -0.011 & $<0.001$ & - & - \\
\hline$\%$ Poverty & -0.043 & $<0.001$ & - & - \\
\hline$\%$ Unemployment & -0.071 & $<0.001$ & - & - \\
\hline$\%<$ HS education & -0.044 & $<0.001$ & - & - \\
\hline \% Homeownership & 0.022 & $<0.001$ & 0.006 & $<0.046$ \\
\hline$\%$ Homes built pre- 1950 & -0.019 & $<0.001$ & -0.017 & $<0.001$ \\
\hline Diversity index & -1.409 & $<0.001$ & -2.523 & $<0.001$ \\
\hline Median HH income & $1.15 \times 10^{-5}$ & $<0.001$ & $0.85 \times 10^{-5}$ & $<0.001$ \\
\hline HPSA & -0.717 & $<0.001$ & - & - \\
\hline
\end{tabular}

$\therefore$ variables in the initial multivariate model before stepwise model selection (both direction) based on BIC and confounder selection.

from Q1 to Q3 with a rate of $0.4 \mathrm{~km}$. The mean distance then increased to $2.6 \mathrm{~km}$ in the Q4 group which was almost 2.4 times farther away than the Q1 census tract group.

In the univariate regression model, all SOD measures were statistically significantly associated with distance to TRI facilities (Table 3). Across the state of $\mathrm{MD}$, census tracts with a higher percentage of non-white residents demonstrated resistance to decaying distance between adjacent TRI facilities (Beta coefficient $=-0.011$; $\mathrm{p}<0.001)$. We observed similar effects in the same direction for \% poverty, \% unemployment, $\%<$ HS education, $\%$ homes built pre-1950 and Diversity Index (Beta coefficient $=-0.043,-0.071,-0.044,-0.019,-1.409$, respectively, with $\mathrm{p}<0.001$ in all these tests). Conversely, $1 \%$ increase in homeownership in census tracts would increase the distance by $0.022 \mathrm{~km}(\mathrm{p}<0.001)$. For income-related variables, a significant increase in income was observed with an increase in distance between a census tract and the closest TRI facility $\left(1.15 \times 10^{-5}\right.$ for median $\mathrm{HH}$ income, $\left.\mathrm{p}<0.001\right)$.

In the multivariate regression model, after performing stepwise variable selection (Additional file 1: Table S1) and evaluating the confounding effects of the SOD factors (Additional file 2: Table S2), \% non-white, \% homes built pre-1950, Diversity index and median $\mathrm{HH}$ income were shown to be significantly associated with TRI facility distance from census tracts $(\mathrm{p}<0.001)$ with $\%$ homeownership as a potential confounder. The direction of the effects remained the same except for \% Hispanic. The direction of the association between distance to TRI facilities and \% Hispanic changed from negative to positive. This is likely due to the adjustment for potential confounders (e.g., \% unemployment, \% less than HS education, and \% homeownership).

Table 4 presents mean distribution of SOD measures in HPSA and non-HPSA tracts based on distance to TRI facilities from census tracts. There were 57 HPSA tracts and 202 non-HPSA tracts that host TRI facilities. There were 117 HPSA tracts and 496 non-HPSA tracts in areas where the distance to the nearest TRI facility from a census tract was from $1 \mathrm{~km}$ to $5 \mathrm{~km}$. In general, \% nonwhite was higher in HPSA tracts that hosted at least one TRI facility than in non-HPSA tracts that hosted at least one TRI facility. Additionally, \% poverty, \% unemployment, \% less than HS education, \% homeownership, and $\%$ homes built pre-1950 were higher in HPSA tracts hosting TRI facilities than in non-HPSA tracts hosting TRI facilities. All the means of SOD measures in HPSA and non-HPSA tracts were statistically different except for \% Hispanic in both host tracts and tracts with nearest TRI facilities at a distance from $1 \mathrm{~km}$ to $5 \mathrm{~km}$ away.

Overall, statistically significant higher levels of \% nonwhite, \% poverty, \% unemployment, \% less than HS

Table 4 Mean distribution of sociodemographic measures by TRI facility buffer zones for 2010 Maryland HSPA tracts and non-HPSA tracts

\begin{tabular}{lcc}
\hline Sociodemographic measures & Host & $\begin{array}{c}\mathbf{1} \mathbf{~ k m}-\mathbf{5} \mathbf{~ k m} \\
\text { buffer }\end{array}$ \\
& HPSA/Non-HPSA & HPSA/Non-HPSA \\
\hline \# Census tracts & $57 / 202$ & $117 / 496$ \\
\hline \% Hispanic & $8.3 / 6.6^{*}$ & $10.3 / 8.2^{*}$ \\
\hline \% Non-white & $55.8 / 33.4$ & $79.8 / 41.9$ \\
\hline \% Poverty & $18.8 / 8.8$ & $16 / 6.5$ \\
\hline \% Unemployment & $11.2 / 6.2$ & $11.1 / 5.5$ \\
\hline \% Less than HS education & $22.2 / 13.3$ & $21 / 9.5$ \\
\hline \% Homeownership & $53.4 / 68.6$ & $47.9 / 73.8$ \\
\hline \% Homes built pre-1950 & $41.5 / 20.9$ & $27.6 / 14.4$ \\
\hline Diversity index & $0.41 / 0.43^{*}$ & $0.37 / 0.45$ \\
\hline Median HH income & $47428 / 70202$ & $48723 / 88798$ \\
\hline
\end{tabular}

*Statistically insignificant at the level of 0.05 . 
education and \% homes built pre-1950 were observed in HPSA tracts than in non-HPSA tracts, regardless of whether or not those areas hosted a TRI facility. Additionally, \% homeownership was lower in HPSA tracts compared to non-HPSA tracts. For the Diversity Index, in areas within $1 \mathrm{~km}$ to $5 \mathrm{~km}$ to a TRI facility, non-HPSA tracts had a higher index than HPSA tracts. Median $\mathrm{HH}$ income was higher in HPSA tracts than non-HPSA tracts, regardless of whether or not the tract hosted a TRI facility.

\section{Discussion}

Our results primarily indicate that people of color, lowincome populations, and persons with less than HS education are located closer to TRI facilities than other groups or there are greater numbers of people of color and lowincome persons in census tracts in areas that host TRI facilities. However, we did observe a lag effect of TRI facilities on the distribution of non-whites across different distance bands with higher percent non-white in the third distance band $(>0.5 \mathrm{~km}$ and $<1 \mathrm{~km})$ compared to the host band $(0 \mathrm{~km})$ and the second distance band $(>0 \mathrm{~km}$ and $<0.5 \mathrm{~km}$ ). For $\%$ poverty and \% less than HS education, we did not observe this lag effect. Univariate regression results reveal statistically significant inverse relationships between distance to TRI facilities and \% Hispanic, \% nonwhite, $\%$ poverty, \% unemployment, \% less than HS education, \% homes built pre-1950, and Diversity index (all statistically significant). Conversely, a positive relationship was observed between distance to TRI facilities and \% homeownership and median $\mathrm{HH}$ income. In the multivariate models, results reveal statistically significant inverse relationships between distance to TRI facilities and \% homes built pre-1950 and Diversity Index, and a positive relationship between distance and median $\mathrm{HH}$ income and \% homeownership. Percent Hispanic changed from negative to positive which may be due to adjustment of other SOD factors in the multivariate model that could act as confounders.

The results of our study mirror results of previous research that demonstrated burden disparities in the distribution of TRI facilities and other LULUs based on race/ethnicity and class [6-18]. The results of this study are most similar to results of recent work in metropolitan Charleston [9] and St. Louis [16] where more TRI facilities were located in census tracts with higher nonwhite and low-income populations. Additionally, Fricker and Hengarter found a direct relationship between racial composition and presence of TRI facilities [7]. Both Ringquist and Neumann et al found TRI facilities were located in people of color neighborhoods $[11,15]$. Unlike Ringquist [15], we did not use zip codes but census tracts as the unit of analysis.

A benefit of including HPSA data is that we can compare HPSA census tracts to non-HPSA census tracts to assess relative differences in the mean distribution of SOD measures by TRI host and buffer zones. This approach is to understand if people of color and disadvantaged groups are both overburdened and medically underserved which is a problem when addressing environmental health disparities. For example, we observed that \% poverty in HPSA census tracts (tracts with insufficient access to primary care) hosting a TRI facility was more than twice the \% poverty in the equivalent nonHPSA census tracts ( $18.8 \%$ and $8.8 \%$, respectively). Furthermore, we found that $\%<\mathrm{HS}$ education population in HPSA census tracts hosting TRI facilities was almost twice that of non-HPSA census tracts $(22.2 \%$ and $13.3 \%$, respectively).

Aside from disparities in mean poverty between HPSA and non-HPSA TRI host census tracts, non-white populations had a higher percentage of persons hosting TRI facilities in HPSA versus non-HPSA tracts (non-white: $55.8 \%, 33.4 \%$, respectively). Additionally, we observed disparities in \% non-white, \% poverty, \% unemployment, and \% less than HS education and also median $\mathrm{HH}$ income in the $1 \mathrm{~km}$ to $5 \mathrm{~km}$ buffer for HPSA vs nonHPSA tracts. The disparity in race, SES, and educational attainment in HPSA versus non-HPSA census tracts is problematic because a higher percentage of these populations live in areas hosting TRI facilities and they lack the salutogenic infrastructure required to act as a buffer against exposure to toxic emissions and other environmental stressors.

This study had several strengths with the first being that all data were from the same year (2010). In studies that use census data, this can only be said once a decade. In addition, this work can contribute to statewide planning as part of PlanMD [68] which is Maryland's comprehensive plan for sustainable growth and development. While these analyses were specific to MD, the methods can be used as a template for other states trying to illustrate the same relationships among SOD composition, presence of pollution-emitting facilities, and health care infrastructure. Another notable strength of this study is that it provides insight into SOD measures other than race/ethnicity that may be a better indicator of spatial disparities in the distribution of TRI facilities within census tracts. Furthermore, our analysis of HPSA versus non-HPSA census tracts hosting TRI facilities can be used by the state to guide the allocation of resources to help reduce toxic releases in vulnerable communities.

After completion of this study, there is still a need for further analyses. We did not measure actual exposure in fenceline communities near each TRI facility or the various buffer zones but rather used distance as a proxy for exposure to TRI facilities. In addition, we did not include TRI emissions data or measure any health outcome data in the buffer zones to show differential 
health status in conjunction with the location of TRI facilities. However, it is worth noting that in terms of effect magnitude some findings we identified via multivariate linear regression were not significant, but they provide an overall trend in the population under study. In reference to HPSA status, additional research is needed to address the potential "double disparity" effect for non-white and economically disadvantaged communities who are living in HPSA tracts that were disproportionately burdened by TRI facilities and may have differential exposure to toxins reported and not reported by facilities under EPCRA.

In the future, we plan to incorporate Risk-Screening Environmental Indicators (RSEI) and National-Scale Air Toxics Assessment (NATA) data from the USEPA in order to conduct a more comprehensive analysis. Specifically, the RSEI database provides information regarding the amount of chemical releases, the fate and transport of the chemical, the route and extent of human exposure to the chemical, the number of people affected, and toxicity [69] which would allow us to better estimate exposure to TRI emissions. Using NATA data would allow us to estimate cancer risk so that we could determine whether there is a disparity in cancer risk in communities hosting TRI facilities. In addition we plan to further examine trends in facility siting and changes in emissions over time from 1990, 2000, and 2010.

One final consideration is whether the use of census tracts is the most appropriate population measure. While there is a wealth of information available at the census tract level, they are often not representative of true neighborhood boundaries. If we decide to represent a real neighborhood analysis in the future, we will have to move away from the use of zip code and census tract analyses in our research particularly for metropolitan statistical areas. We see potential in the approach taken by the Baltimore Neighborhood Indicators Project [70] to measure and track 'actual' neighborhood level social, environmental, and health data. We also believe that the use of planning districts or councilmatic districts may be a useful alternative to census tracts.

\section{Conclusion}

This information may be useful to community-based organizations seeking to obtain information on the spatial distribution of TRI facilities and assistance from federal agencies such as the USEPA and the Agency for Toxic Substances and Disease Registry (ATSDR) to study the negative health impacts of these sites as part of a comprehensive community revitalization program. In addition, state agencies such as the MD Department of the Environment and the MD DHMH may be able to use the results of this study in its efforts to prioritize areas in vulnerable communities with a high concentration of TRI facilities and toxic releases and leverage state resources to clean up areas, improve public health, and enhance quality of life and community sustainability.

Additionally, this work has utility in providing metrics for how federal and state regulatory programs are meeting goals to reduce environmental injustice and environmental health disparities including cumulative impacts of environmental hazards in environmental justice communities. In addition, this work can contribute to statewide efforts to reduce health disparities and achieve health equity through implementation of the Affordable Care Act or state laws such as the MD Health Improvement and Health Disparities Reduction Act. With the right investment of ACA resources, hospitalizations, emergency room visits, and overall burden of disease related to exposure to toxins and other agents could be reduced in overburdened and underserved areas.

\section{Additional files}

Additional file 1: Table S1. BIC Stepwise Model Selection on Both Directions. Additional file 2: Table S2. Confounder Selection (Each possible confounder was added sequentially).

\section{Abbreviations}

TRI: Toxic release inventory; SOD: Sociodemographic; USEPA: United States Environmental Protection Agency; HPSA: Health Professional Shortage Area; SES: Socioeconomic status; MDHMH: Maryland Department of Health and Mental Hygiene; EPHTN: Environmental Public Health Tracking Network; NATA: National-Scale Air Toxics Assessment; MD: Maryland; GIS: Geographic information systems; EPCRA: Emergency Planning and Community Right-toKnow Act; RSEl: Risk-Screening Environmental Indicators; HH: Household; HS: High school; HEZ: Health Enterprise Zone; MHIHDRA: Maryland Health Improvement and Health Disparities Reduction Act; POTWs: Publicly Operated Treatment Works; LULUs: Locally unwanted land uses; MPEMHD: Maryland Plan to Eliminate Minority Health Disparities; DHHS: Department of Health and Human Services; MSA: Metropolitan statistical area; FRS: Federal Registry System; ATSDR: Agency for Toxic Substances for Disease Registry; BIC: Bayesian Information Criterion.

\section{Competing interests}

There are no financial or non-financial competing interests to disclose.

\section{Author's contributions}

RR drafted the manuscript. CJ designed and performed the statistical analysis and mapping. KB assisted with drafting, reviewing, and editing the manuscript. RM assisted with reviewing and editing the manuscript. $\mathrm{HZ}$ assisted with reviewing and editing the manuscript. CN assisted with reviewing and editing the manuscript. SW designed the study and assisted with drafting the manuscript. All authors read and approved the final manuscript.

\section{Acknowledgements}

We would like to acknowledge the support of faculty, staff, and students at the University of Maryland-College Park, Program on Community Engagement, Environmental Justice and Health (CEEH), and the University of Memphis.

\section{Author details}

${ }^{1}$ Community Engagement, Environmental Justice and Health, University of Maryland-College Park, College Park, MD 20742, USA. ${ }^{2}$ Maryland Institute for Applied Environmental Health, University of Maryland-College Park, College Park, MD 20742, USA. ${ }^{3}$ Epidemiology, Biostatistics, and Environmental Health Science, School of Public Health, University of Memphis, Memphis, TN 38111, USA. 
Received: 2 July 2013 Accepted: 24 March 2014

Published: 4 April 2014

\section{References}

1. Wilson S: An ecologic framework to study and address environmental justice and community health issues. Environ Justice 2009, 2(Suppl 1):15-24.

2. Wilson SM: Environmental justice movement: a review of history, research, and public health issues. J Publ Manage Soc Pol 2010, 16:19-50.

3. Morello-Frosch R, Lopez R: The riskscape and the color line: examining the role of segregation in environmental health disparities. Environ Res 2006, 102:181-196.

4. Morello-Frosch R, Pastor M, Sadd J: Environmental justice and southern California's "riskscape": the distribution of air toxics exposures and health risks among diverse communities. Urban Aff Rev 2001, 36:551-578.

5. Bullard RD, Mohai P, Saha R, Wright B: Toxic Wastes and Race at Twenty, 1987-2007: Grassroots Struggles to Dismantle Environmental Racism in the United States. In A Report for the United Church of Christ Justice and Witness Ministries. Cleveland, OH: United Church of Christ; 2007.

6. Perlin SA, Setzer RW, Creason J, Sexton K: Distribution of industrial air emissions by income and race in the United States: an approach using the toxic release inventory. Environ Sci Technol 1995, 29:69-80.

7. Fricker RD, Hengartner NW: Environmental equity and the distribution of toxic release inventory and other environmentally undesirable sites in metropolitan New York City. Environ Ecol Stat 2001, 8:33-52.

8. Allen DW: Social class, race, and toxic releases in American counties 1995. Soc Sci J 2001, 38:13-25.

9. Wilson SM, Fraser-Rahim H, Williams E, Zhang H, Rice L, Svendsen E, Abara W: Assessment of the distribution of toxic release inventory facilities in metropolitan Charleston: an environmental justice case study. AJPH 2012, 102:1974-1980.

10. Scott M, Cutter SL, Menzel C, Ji M, Wagner D: Spatial accuracy in EPA's environmental hazards databases and their use in environmental equity analyses. App/ Geogr Stud 1997, 1(1):45-46.

11. Neumann CM, Forman DL, Rothlein JE: Hazard screening of chemical releases and environmental equity analysis of populations proximate to toxic release inventory facilities in Oregon. Environ Health Persp 1998, 106:217-226.

12. Neumann CMC: Improving the U.S. EPA toxic release Inventory database for environmental health research. J Toxicol Environ Health B Crit Rev 1998, $1: 259-270$.

13. Pastor M Jr, Sadd JL, Morello-Frosch R: Waiting to inhale: the demographics of toxic air release facilities in 21st-century California. Soc Sci Q 2004 85:420-440

14. Morello-Frosch R, Jesdale BM: Separate and unequal: residential segregation and estimated cancer risks associated with ambient air toxics in U.S. metropolitan areas. Environ Health Perspect 2006, 114:386-393.

15. Ringquist EJ: Equity and the distribution of environmental risk: the case of TRI facilities. Soc Sci Q 1997, 78:811-829.

16. Abel TD: Skewed riskscapes and environmental injustice: a case study of metropolitan St. Louis. Environ manage 2008, 42(Suppl 2):232-248.

17. Daniels G, Friedman S: Spatial inequality and the distribution of industrial toxic releases: evidence from the 1990 TRI. Soc Sci Q 1999, 80(2):244-262

18. Morello-Frosch R, Pastor M Jr, Porras C, Sadd J: Environmental justice and regional inequality in southern California: implications for future research. Environ Health Perspect 2002, 110(Suppl 2):149-154.

19. Heaney CD, Wilson SM, Wilson OR: The west end revitalization association's community-owned and managed research model: development, implementation, and action. Prog Community Health Partnersh 2007, 1(Suppl 4):339-349.

20. Wilson SM, Wilson OR, Heaney CD, Cooper J: Use of EPA collaborative problem-solving model to obtain environmental justice in North Carolina. Prog Community Health Partnersh 2007, 1(Suppl 4):327-337.

21. Wilson SM, Howell F, Wing S, Sobsey M: Environmental injustice and the Mississippi hog industry. Environ Health Perspect 2002, 110(suppl 2):195-201.

22. Wing S, Cole D, Grant G: Environmental injustice in North Carolina's hog industry. Environ Health Perspect 2000, 108:225-231.

23. Martuzzi M, Mitis F, Forastiere F: Inequalities, inequities, environmental justice in waste management and health. Eur J Publ Health 2010, 20(Suppl 1):21-26.

24. Noonan DS, Turaga RM, Baden BM: Superfund, hedonics, and the scales of environmental justice. Environ Manage 2009, 44(Suppl 5):909-920.
25. Mohai P, Lantz PM, Morenoff J, House JS, Mero RP: Racial and socioeconomic disparities in residential proximity to polluting industria facilities: evidence from the Americans' changing lives study. Am J Publ Health 2009, 99(Suppl 3):S649-S656.

26. Wilson SM, Burwell K, Abara W: Environmental justice and infectious disease: gaps, issues, and research needs. Environ Justice 2012, 5(Suppl 1):8-20.

27. Mohai $P$, Saha R: Reassessing racial and socioeconomic disparities in environmental justice research. Demography 2006, 43(Suppl 2):383-399.

28. Payne-Sturges D, Gee G: National environmental health measures for minority and low-income populations: tracking social disparities in environmental health. Environ Res 2006, 102(Suppl 2):154-171.

29. Gee GC, Payne Sturges DC: Environmental health disparities: a framework integrating psychosocial and environmental concepts. Environ Health Persp 2004, 112(17):1645-1653.

30. Wilson S, Heaney C, Cooper J, Wilson O: Built environment issues in unserved and underserved African-American neighborhoods in North Carolina. Environ Justice 2008, 1(Suppl 2):63-72.

31. Wilson S, Hutson M, Mujahid M: How planning and zoning contribute to inequitable development, neighborhood health, and environmental injustice. Environ Justice 2008, 1(Suppl 4):211-216.

32. Cutter S, Boruff B, Shirley W: Social vulnerability to environmental hazards. Soc Sci Q 2003, 84(Suppl 2):242-261

33. Miranda MLM, Keating MHM, Edwards SES: Environmental justice implications of reduced reporting requirements of the toxics release inventory burden reduction rule. Environ Sci Technol 2008, 42:5407-5414.

34. US EPA: Table 3. Chronic (non-cancer) toxicity data for chemicals listed under EPCRA Section 313. 1995. http://www.epa.gov/tri/trichemicals/hazardinfo/ hazard_chronic_non-cancer95.pdf.

35. US EPA: Table 4. Cancer data for chemicals listed under EPCRA section 313. 1995. http://www.epa.gov/tri/trichemicals/hazardinfo/hazard_cancer95.pdf.

36. US EPA: Table II. EPCA section 313 chemical list for reporting year 2012 (including toxic chemical categories). http://www.epa.gov/tri/trichemicals/ chemicallists/RY2012ChemicalList.pdf.

37. Chakraborty J: The geographic distribution of potential risks posed by industrial toxic emissions in the U.S. J Environ Sci Health A Tox Hazard Subst Environ Eng 2004, 39:559-575.

38. Luo J, Hendryx M: Environmental carcinogen releases and lung cancer mortality in rural-urban areas of the United States. J Rural Health 2011, 27:342-349.

39. Chakraborty J, Maantay JA: Proximity Analysis for Exposure Assessment in Environmental Health Justice Research. Dordrecht: Springer Netherlands; 2011:111-138.

40. Ostro BB, Broadwin RR, Green SS, Feng W-YW, Lipsett MM: Fine particulate air pollution and mortality in nine California counties: results from CALFINE. Environ Health Persp 2006, 114:29-33.

41. Hutson M, Wilson SM: The role of community-based strategies in addressing metropolitan segregation and racial health disparities. Community Dev 2011, 42:476-493

42. Bodenheimer T, Pham HH: Primary care: current problems and proposed solutions. Health Aff 2010, 29:799-805

43. Liu JJ: Health professional shortage and health status and health care access. J Health Care Poor Underserved 2007, 18:590-598.

44. Chin MH, Walters AE, Cook SC, Huang ES: Interventions to reduce racial and ethnic disparities in health care. Medicare Medicaid Res Rev 2007, 64(Suppl 5):7-28.

45. Hendryx M: Mental health professional shortage areas in rural Appalachia. J Rural Health 2008, 24:179-182.

46. Jha AK, Fisher ES, Li Z, Orav EJ, Epstein AM: Racial trends in the use of major procedures among the elderly. N Engl J Med 2005, 353:683-691.

47. Williams DR, Collins C: Racial residential segregation: a fundamental cause of racial disparities in health. Publ Health Rep 2001, 116(Suppl 5):404-416.

48. Mayberry RM, Mili F, Ofili E: Racial and ethnic differences in access to medical care. Med Care Res Rev 2000, 57(Suppl. 1):108-145.

49. Fiscella K, Franks P, Gold MR, Clancy CM: Inequality in quality: addressing socioeconomic, racial, and ethnic disparities in health care. J Amer Med Assoc 2000, 283:2579-2584.

50. Fiscella K, Williams DR: Health disparities based on socioeconomic inequities: implications for urban health care. Acad Med 2004, 79(Suppl 12):1139-1147.

51. Saha S, Arbelaez JJ, Cooper LA: Patient-physician relationships and racial disparities in the quality of health care. Am J Publ Health 2003, 98(Suppl 10):1713-1719. 
52. Williams DR, Rucker TD: Understanding and addressing racial disparities in health care. Health Care Financ R 2000, 21(Suppl 4):75-90.

53. Blankfield RP, Goodwin M, Jaen CR, Stange KC: Addressing the unique challenges of inner-city practice: a direct observation study of inner-city, rural, and suburban family practices. J Urban Health 2002, 79(Suppl 2):173-195.

54. Szilagyi PG, Schaffer S, Shone L, Barth R, Humiston SG, Sandler M, Rodewald LE: Reducing geographic, racial, and ethnic disparities in childhood immunization rates by using reminder/recall interventions in urban primary care practices. Pediatrics 2002, 110(Suppl 5):1-8.

55. McConnochie KM, Russo MJ, McBride JT, Szilagyi PG, Brooks AM, Roghmann $\mathrm{KJ}$ : Socioeconomic variation in asthma hospitalization: excess utilization or greater need? Pediatrics 1999, 103(6):e75-e75.

56. Maryland Department of Health and Mental Hygiene (MDHMH): Maryland plan to eliminate minority health disparities plan of action. 2010-2014 www. astho.org/Programs/Health-Equity/Maryland-Health-Equity-Report/.

57. Maryland Health Services Cost Review Commission (HSCRC) asthma and acute myocardial infarction inpatient hospitalizations (2000-2006). http://phpa. dhmh.maryland.gov/OEHFP/EH/Shared\%20Documents/MD-MetadataHosp-090126.pdf.

58. Mather FJ, White LE, Langlois EC, Shorter CF, Swalm CM, Shaffer JG, Hartley WR: Statistical methods for linking health, exposure, and hazards. Environ Health Persp 2004, 112:1440-1445.

59. Maryland Department of Health and Mental Hygiene Environmental Public Health Tracking Website. http://eh.dhmh.md.gov/idehaweb/query.aspx.

60. U.S. Census Bureau: 2010 Census Interactive Population Search. http://www.census.gov/2010census/popmap/ipmtext.php?fl=24.

61. Stat USDOCU: 2010 Census Summary File 1. 2012.

62. Stat USDOCU: 2010 Census Summary File 2. 2012.

63. Meyer $P$, Mclntosh S: The USA today index of ethnic diversity. Int J Publ Opin Res 1992, 4:51-58.

64. US EPA: The emergency planning and community right-to-know act. http://www.bhs.idaho.gov/Resources/PDF/EPCRA_Fact_Sheet.pdf.

65. Trivedi AN, Zaslavsky AM, Schneider EC, Ayanian JZ: Relationship between quality of care and racial disparities in medicare health plans. JAMA 2006, 296:1998-2004.

66. Zuvekas SH, Taliaferro GS: Pathways to access: health insurance, the health care delivery system, and racial/ethnic disparities, 1996-1999. Health Aff (Millwood) 2003, 22:139-153.

67. R: a language and environment for statistical computing [http://www.R-project.org]

68. Planning MDO, Planning MDO: PlanMaryland: revised draft plan. 2011

69. U.S. EPA: Risk-Screening Environmental Indicators (RSEI). How to use-and not use-RSEl. 2012. http://www.epa.gov/opptintr/rsei/pubs/using_rsei.html.

70. Baltimore Neighborhoods Indicators Alliance. http://www.bniajfi.org/.

\section{doi:10.1186/1476-069X-13-26}

Cite this article as: Wilson et al:: Being overburdened and medically underserved: assessment of this double disparity for populations in the state of Maryland. Environmental Health 2014 13:26.

\section{Submit your next manuscript to BioMed Central and take full advantage of:}

- Convenient online submission

- Thorough peer review

- No space constraints or color figure charges

- Immediate publication on acceptance

- Inclusion in PubMed, CAS, Scopus and Google Scholar

- Research which is freely available for redistribution 